\title{
Neutrophil Elastase Inhibitor Increases Flap Survival in Experimental Degloving Injuries
}

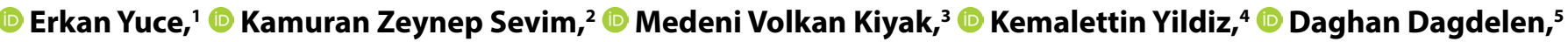 \\ (D) Fatih Irmak, ${ }^{2}$ (D) Semra Karsidag, ${ }^{2}$ (D) Ulkan Kilic ${ }^{4}$ \\ 'Department of Plastic Reconstructive and Aesthetic Surgery, Kirikkale Yuksek Ihtisas Hospital, Kirikkale, Turkey \\ ${ }^{2}$ Department of Plastic Reconstructive and Aesthetic Surgery, Sisli Hamidiye Etfal Training and Research Hospital, Istanbul, Turkey \\ ${ }^{3}$ MVK Aesthetic Clinic, Istanbul, Turkey \\ ${ }^{4}$ Department of Plastic Reconstructive and Aesthetic Surgery, Bezmialem Foundation University, Istanbul, Turkey \\ ${ }^{5}$ Department of Plastic Reconstructive and Aesthetic Surgery, Trakya University Faculty of Medicine, Edirne, Turkey
}

\begin{abstract}
Objectives: Degloving hand injuries have generally been viewed as among the most difficult of injuries to manage due to the extensive nature of associated damage. The traditional approach to the circumferentially degloved segment of problematic flap viability has been to resuture the flap and to wait and see. However, the waiting period or the specific hemorheological protocol remains uncertain. This study aims to acknowledge if Sivelestat, known to ameliorate ischemia-reperfusion injury, enhances the survival of avulsed flaps in a hind limb degloving model of rats and to compare Sivelestat's effects to Pentoxifylline.

Methods: In this study, total flap area $\left(\mathrm{cm}^{2}\right)$, area of necrosis in the flap $\left(\mathrm{cm}^{2}\right)$, and the ratio between the necrotic and total areas (percentage) were determined. Angiogenesis among the groups was documented with CD31, anti-PECAM staining. TUNEL assay was performed to allow the visualization of cell nuclei containing fragmented DNA, a typical feature of apoptosis.

Results: The findings obtained in this study showed that Sivelestat administered at $10 \mathrm{mg} / \mathrm{kg} / \mathrm{hour}$ dosage will inhibit the ischemia-reperfusion injury more pertinently than Pentoxifylline, which exerts only hemorheological effects.

Conclusion: The anti-inflammatory effects of Sivelestat will be beneficial for decreasing the early complications of degloving injury, such as inflammation, sepsis, and edema, better than Pentoxifylline, which exerts only hemorheological effects.

Keywords: Degloving injury; neutrophil elastase inhibitor; ischemia reperfusion injury.
\end{abstract}

Please cite this article as "Yuce E, Sevim KZ, Kiyak MV, Yildiz K, Dagdelen D, Irmak F, et al. Neutrophil Elastase Inhibitor Increases Flap Survival in Experimental Degloving Injuries. Med Bull Sisli Etfal Hosp 2020;54(2):169-175".

A vulsion and degloving injuries arises from a vast array of mechanisms, machines and situations, in which the hand is injured with low energy shearing forces in a rigid position. ${ }^{[1]}$ These types of injuries have generally been viewed as among the most problematic of injuries to manage due to their extensive nature of associated damage. During degloving injuries, blood vessels having high elasticity are disembodied and separated with irreversible injury along the entire length of involvement, and so are the tendons and nerves. Furthermore, in circumferential degloving injuries, the distal flap goes through a state of abrupt ischemia followed by reverse perfusion forming after the reattachment of the flaps back to its' origin. Arnez et al. ${ }^{[2]}$ recently reclassified degloving injuries according to

Address for correspondence: Erkan Yuce, MD. Kirikkale Yuksek Ihtisas Hastanesi, Plastik Rekonstruktif ve Estetik Cerrahi Klinigi, Kirikkale, Turkey Phone: +90 5302850230 E-mail: drerkanyuce@gmail.com

Submitted Date: July 19, 2018 Accepted Date: July 24, 2018 Available Online Date: July 25, 2018

${ }^{\circ}$ Copyright 2020 by The Medical Bulletin of Sisli Etfal Hospital - Available online at www.sislietfaltip.org

OPEN ACCESS This is an open access article under the CC BY-NC license (http://creativecommons.org/licenses/by-nc/4.0/). 
the extension of the injury mechanism into four groups: a) circumscribed degloving injury that arises from tangential forces, b) non-circumferential degloving, c) single and d) multiplane circumferential degloving injury. Among many options of treating a degloving injury are: salvaging the degloved segment through conservative therapy with dressing, debriding and skin grafting, maintaining vascularity by arterial anastomosis or arteriovenous shunting; and coverage by free flaps if the segments are not salvageable. ${ }^{[3-5]}$ The traditional approach to the circumferentially degloved segment of problematic flap viability has been to resuture the flap and to wait and see. However, the waiting period or the specific treatment protocol remains uncertain. Sivelestat ${ }^{\oplus}, \mathrm{N}-\{2-[(\{4-[(2$, dimethylpropanoyl)oxy]phenyl\}sulfonyl) amino]benzoyl glycine (Ono Pharmaceutical, Osaka, Japan) is a specific neutrophil elastase inhibitor which found use in ameliorating acute systemic inflammatory response syndrome, acute respiratory distress syndrome and in ischemia-reperfusion injury forming after crush syndrome. ${ }^{[6-8]}$

Pentoxifylline is a competitive nonselective phosphodiesterase inhibitor, which raises the intracellular CAMP, activates pkA, inhibits TNF and leukotriene synthesis. In addition, pentoxifylline improves red blood cell deformability and decreases the potential for platelet aggregation. ${ }^{[9-11]}$ Experimental studies show that pentoxifylline increases perfusion in myocutaneous and skin flaps.

Allopurinol is a purine analog and an inhibitor of xanthine oxidase and through its antioxidant effects, it is found to be beneficial in ischemia-reperfusion injuries. ${ }^{[9-11]}$

This study aims to acknowledge if Sivelestat, known to ameliorate IRI, enhances the survival of avulsed flaps in a hind limb degloving model of rats, which was described by Milcheski et al. and to compare Sivelestat's effects to a wellknown hemorheological agent, Pentoxifylline.

\section{Methods}

\section{Experiment}

Upon obtaining the necessary ethics committee approval for animal experimentation, this study was initiated. A total of 24 male Wistar rats, weighing between 250 and 350 $\mathrm{g}$, were used in this experiment and divided into three groups, eight rats in each group. Animals were anesthetized with $35 \mathrm{mg} / \mathrm{kg}$ Ketamine (Ketalar ${ }^{\circledast}$, Pfizer, Istanbul) and $5 \mathrm{mg} / \mathrm{kg}$ Xylazine(Rompun ${ }^{\circledR}$, Bayer, Istanbul) intramuscularly. An incision was made on the right groin over the inguinal ligament, including the skin and subcutaneous tissue. Degloving injury model has been adapted from the Laboratory of Microsurgery, Division of Plastic Surgery of Sao Paulo. ${ }^{[10]}$ Briefly, the right hind limb was incised circumferentially at the inguinal ligament level. Four Backhaus clamps were positioned in the four quadrants $(3,6,9$, and 12 o'clock positions). A distal traction force was applied to the flap, enough to pull the flap to the ankle region (Fig. 1). This maneuver created a reverse-flow flap going through the ischemia-reperfusion cycle. After a downtime of five minutes, the flap was sutured back to its original place and the incision was closed with 5/0 nylon sutures. The rat's tail vein was cannulated with a $16 \mathrm{G}$ catheter for pharmacological interventions.

In group 1, which was also described as the control group, $1 \mathrm{cc}$ of saline through the tail vein was administered. In group 2, which was described as the Pentoxifylline group, $1 \mathrm{cc}$ of pentoxifylline $(25 \mathrm{mg} / \mathrm{kg})$, (Trental ${ }^{\oplus}$, Hoechst pharmaceutical industry, Istanbul) was administered through the tail vein as a single injection given gradually. In group 3 , which was the Sivelestat group, $1 \mathrm{cc}(10 \mathrm{mg} / \mathrm{kg})$ of Sivelestat ${ }^{\oplus}$ was administered after creating the degloved flap. ${ }^{[12]}$ Fluid replacement with saline was conducted $2 \mathrm{cc} / \mathrm{kg} /$ hour dosage throughout the experiment. Bacitracin was utilized for wound dressing purposes and the rats were observed daily in terms of flap survival for seven days. At the end of this period, the rats were sacrificed by an overdose of Thiopental. No signs of autophagy were observed in the avulsed flaps. In group 1 animals, signs of infection were observed in three animals. The total area of flap necrosis was calculated using Image J software (National Institutes of Health, $\mathrm{NIH}$, USA). Total flap area $\left(\mathrm{cm}^{2}\right)$, area of necrosis in the flap $\left(\mathrm{cm}^{2}\right)$, and the ratio between the necrotic and total areas (percentage) were determined (Fig. 2a-c, Fig. 3)

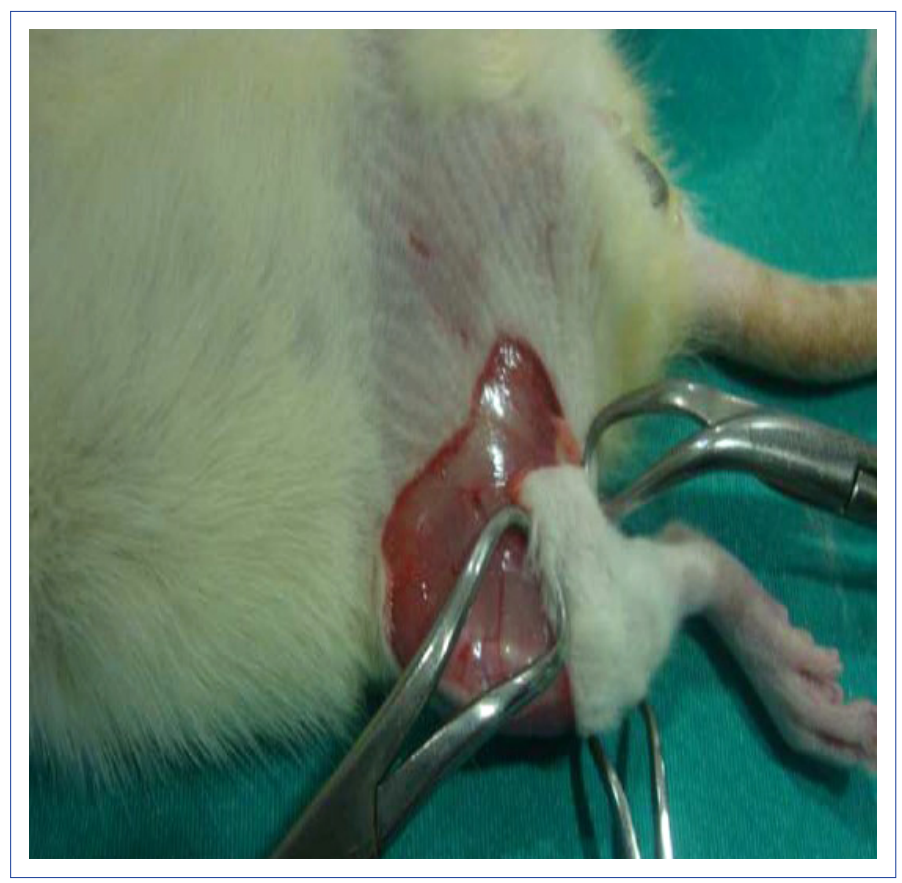

Figure 1. Degloving injury model of the lower extremity. 


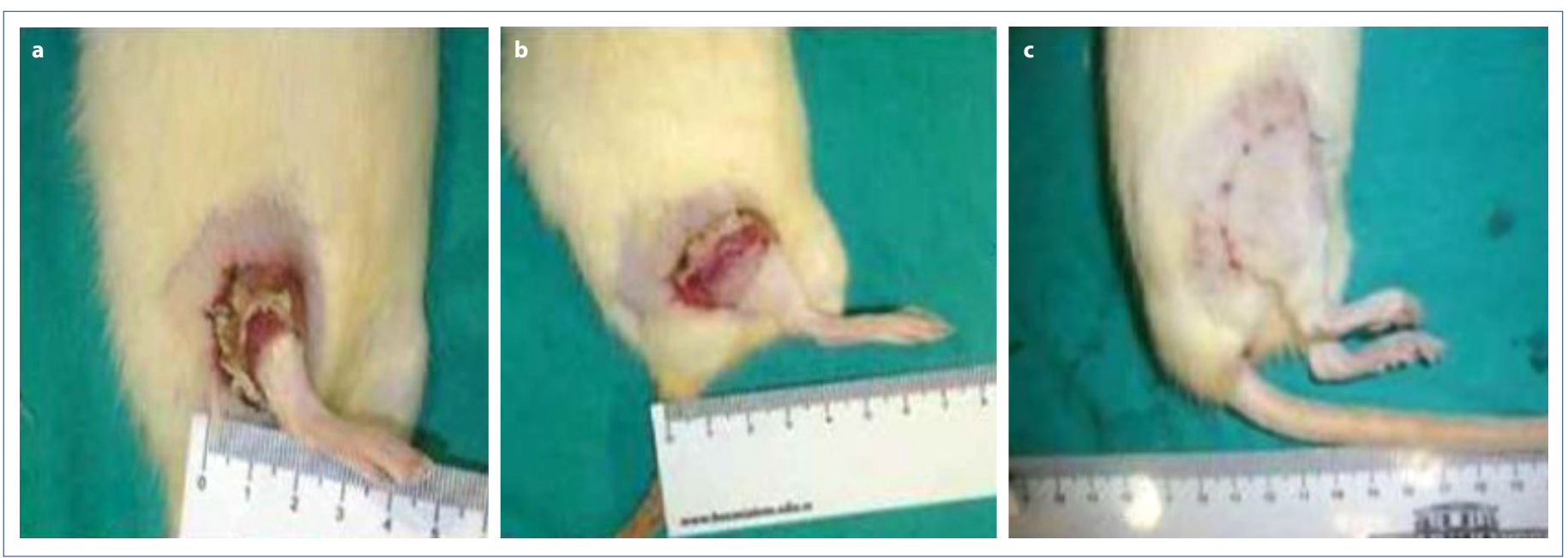

Figure 2. Macroscopic view of the avulsed flap on postoperative day seven in groups 1,2 and 3.

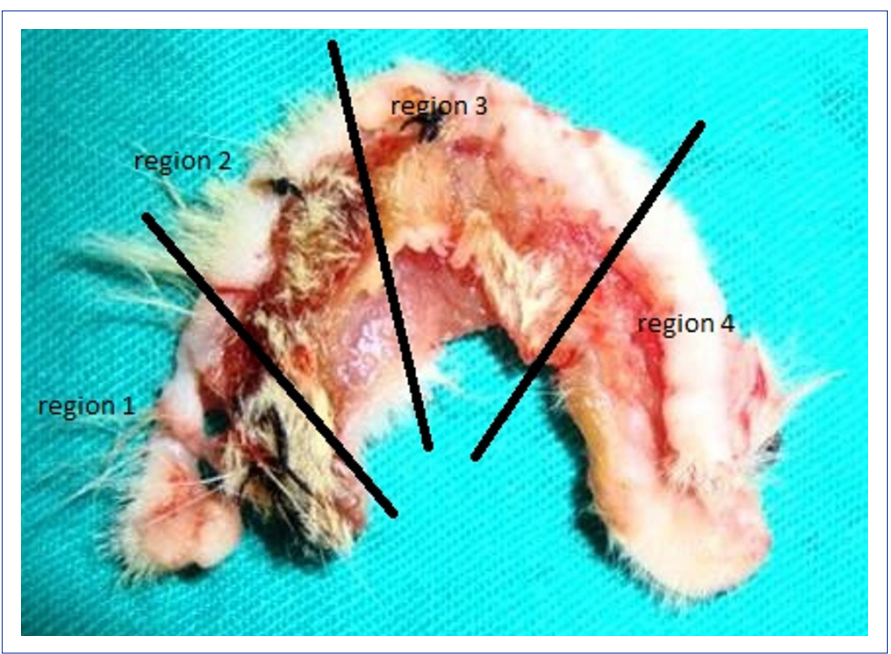

Figure 3. Schematic view of the avulsed flap segment divided into four regions.

(Table1). In order to determine the amount of angiogenesis among the groups, CD31, anti-PECAM staining was performed as described below. The amount of angiogenesis was determined using Image $J$ analysis (Fig. 4a-c). Analysis of apoptotic cells was made by the TUNEL assay (Terminal deoxynucleotidyl transferase dUTP Nick End Labeling) method.

\section{Immunofluorescence Protocol}

The degloved flap was excised en-bloc as a pathology specimen, frozen on dry ice and cut on a cryostat into 20 $\mu \mathrm{m}$ horizontal sections (Leica Instruments, Wetzlar, Germany). Skin sections were fixed in $4 \%$ paraformaldehyde in $0.1 \mathrm{M}$ phosphate-buffered saline, rinsed, pretreated for antigen retrieval with $0.1 \mathrm{M}$ phosphate-buffered saline containing $1 \%$ sodium dodecyl sulfate, rinsed and immersed for $1 \mathrm{~h}$ in $0.1 \mathrm{M}$ phosphate-buffered saline containing $0.3 \%$ Triton X-100 and 10\% normal donkey serum. The sections were incubated overnight at $4{ }^{\circ} \mathrm{C}$ with polyclonal goat antiPECAM-1 (CD31) (\#sc1506; SANTA CRUZ), (diluted 1:100 in $0.1 \mathrm{M}$ phosphate-buffered saline) that were detected with Alexa Fluor 488 donkey anti-goat (A11055; INVITROGEN) secondary antibody. Sections were counterstained with 40-6-diamidino-2-phenylindole (DAPI). Sections were evaluated under a fluorescence microscope (NIKON ECLIPSE Ni) connected to a CCD camera (NIKON DS-Fi1c). Rate of angiogenesis (CD31+ cells) was analysed in a blinded way by five independent examiners through counting numbers of cells or profiles in four randomly defined regions of interests per tissue measuring $62.500 \mu \mathrm{m}^{2}$. Two sections were processed for each animal. Mean values were calculated for both sections for all specimens (Fig. 3). ${ }^{[13]}$

Table 1. Total Flap Area (cm2), the Necrotic Area in the flap (cm2386), and the ratio between necrotic and Total Areas (\%)

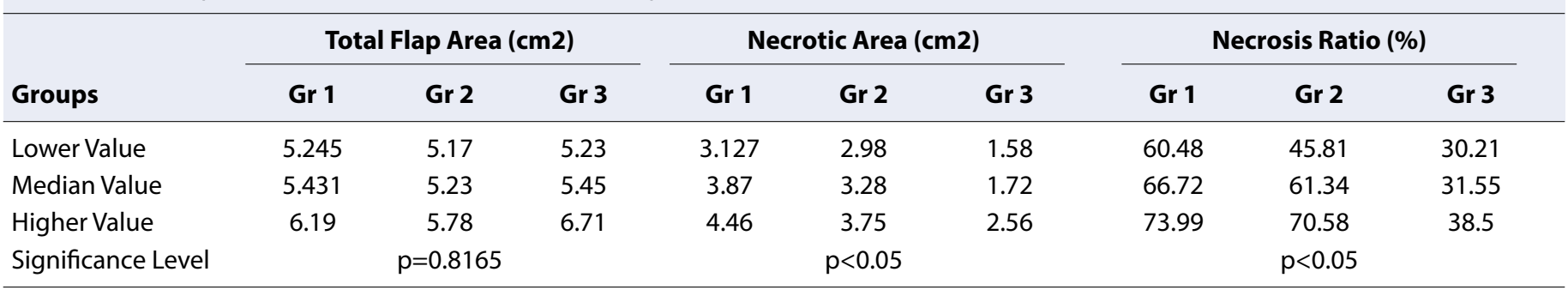




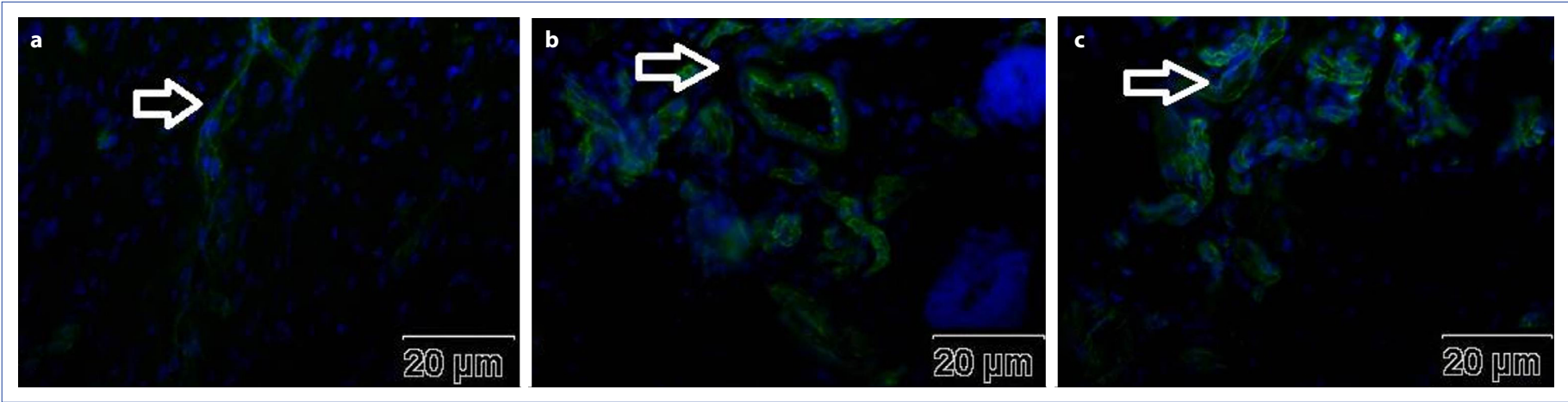

Figure 4. (a) Immunohistochemical staining for the endothelial marker of angiogenesis CD31 were assessed in the control group. Arrow shows capillary formation stained with CD31. (b) Immunohistochemical staining for the endothelial marker of angiogenesis CD31 were assessed in the pentoxifylline group. Arrow shows capillary formation stained with CD31. (c) Immunohistochemical staining for the endothelial marker of angiogenesis CD31 were assessed in the sivelestat group. Sivelestat treated group showed an increase in the capillaries to approximately $200 \%$ of baseline from saline treated rats. Arrow shows capillary formation stained with CD31.

\section{TUNEL Assay}

Analysis of DNA-fragmented cells from the sections harvested from animals was stained by terminal transferase fluorescein-dUTP nick end labeling (TUNEL), using a commercially available kit (11684795910, ROCHE, Switzerland). In these sections, DNA-fragmented cells were counted in a blinded manner in four randomly defined regions in the epidermis (each $62.500 \mu \mathrm{m}^{2}$ ) as above. ${ }^{[14]}$ Apoptotic cells were identified by the characteristics of nuclear condensation, fragmentation and margination (Fig. 5a-c) (Table 2, 3).

\section{Statistical Analysis}

The results were expressed in the form of mean \pm SD. Serially measured parameters were compared with two-way analysis of variance (ANOVA-Tukey test). Kruskal-Wallis non-parametric test for independent samples among the three groups was performed. Inter-observer results correlated well and the significance level was $95 \%(p<0.05)$.

\section{Results}

Animals: One animal from Group 2 (Pentoxifylline) was excluded from this study due to unsuspected death in the first postoperative night, according to the exclusion criteria. Other exclusion criteria consisted of diarrhea and significant weight loss throughout the experiment. Sivelestat group rats displayed minor inflammation on injury sites macroscopically during the wound healing process of the avulsed flap.

Total flap area planimetry: The total flap area $\left(\mathrm{cm}^{2}\right)$, the necrotic area in the flap $\left(\mathrm{cm}^{2}\right)$, and the ratio between necrotic and total areas (\%) were determined using Image J analysis in each group after seven days. The total flap area $\left(\mathrm{cm}^{2}\right)$ was 6.19 for the control group, 5.78 for the Pentoxifylline group, and 6.71 for the Sivelestat group. Total flap areas were statistically similar $(p=0.8165)$. The ratio between the avulsed flap necrotic area and total area in the control group was $66.72 \%, 61.3 \%$ in the Pentoxifylline group and $31.5 \%$ in the Sivelestat applied group. The ANOVA-Tukey analysis showed significant differences between pairs, con-

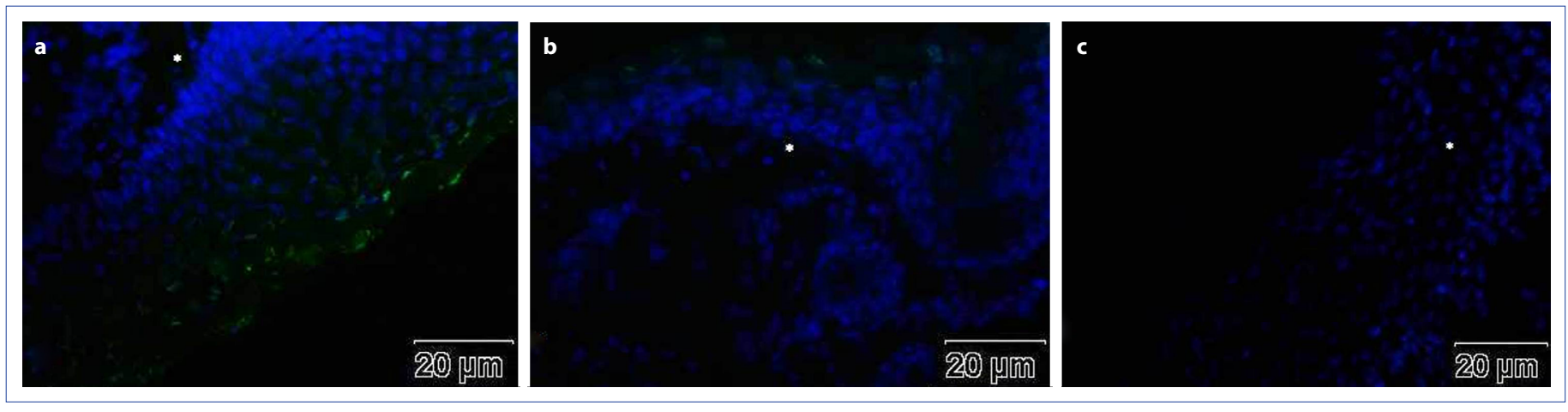

Figure 5. TUNEL and Roche staining of nonviable flaps. Apoptotic cell nuclei stained by TUNEL in the dermis of the flap. (a) Saline (b) Pentoxifylline (c) Sivelestat. TUNEL+ cell nuclei revealed brighter fluorescence shown by arrow. Asterix shows chromatin condensation. There was a significant difference between saline and sivelestat groups, also between pentoxifylline and sivelestat groups $(p<0.05)$. 
Table 2. Summary of Manual Microvessel Counts

\begin{tabular}{lcccc}
\hline Examiner & $\begin{array}{c}\text { Group } \\
\text { Saline* }\end{array}$ & $\begin{array}{c}\text { Group } \\
\text { Pentoxyfilline* }\end{array}$ & $\begin{array}{c}\text { Group } \\
\text { Sivelestat* }\end{array}$ & p \\
\hline 1 & $7.5 \pm 1.18$ & $16.84 \pm 3.51$ & $30.6 \pm 4.28$ & 0.006 \\
2 & $9.25 \pm 1.01$ & $14.0 \pm 3.28$ & $26.0 \pm 3.61$ & 0.012 \\
3 & $7.45 \pm 1.34$ & $15.21 \pm 2.44$ & $27.1 \pm 1.51$ & 0.032 \\
4 & $9.01 \pm 1.05$ & $17.11 \pm 3.21$ & $37.03 \pm 1.24$ & 0.054 \\
5 & $6.81 \pm 1.68$ & $16.0 \pm 2.64$ & $29.02 \pm 1.06$ & 0.008 \\
Summary** & & & & $\mathrm{p}<0.05$ \\
\hline
\end{tabular}

*Mean microvessel count per high power field (200x) \pm Standard Error; **p value determined by ANOVA, Overall statistical significance as determined by repeated measures analysis of variance.

Table 3. TUNEL + cells counted by region

\begin{tabular}{lcccc}
\hline & $\begin{array}{c}\text { Group } \\
\text { Saline } \\
\text { (Med } \pm \text { S.D) }\end{array}$ & $\begin{array}{c}\text { Group } \\
\text { Pentoxyfilline } \\
\text { (Med } \pm \text { S.D) }\end{array}$ & $\begin{array}{c}\text { Group } \\
\text { Sivelestat } \\
\text { (Med } \pm \text { S.D) }\end{array}$ & p \\
\hline Region 1 & $31.7 \pm 22.5$ & $25.7 \pm 16.1$ & $3.0 \pm 4.1$ & 0.019 \\
Region 2 & $36.5 \pm 22.8$ & $20.2 \pm 13.1$ & $14.3 \pm 8.1$ & 0.07 \\
Region 3 & $41.3 \pm 23.1$ & $29.0 \pm 19.7$ & $7.3 \pm 9.9$ & 0.019 \\
Region 4 & $48.5 \pm 28.6$ & $34.7 \pm 17.2$ & $9.3 \pm 8.8$ & 0.012 \\
\hline
\end{tabular}

ANOVA(Tukey Test); $p<0.05$, statististically significant.

trol and pentoxifylline group $(p<0.01)$ and control and Sivelestat $(p<0.01)$. There was also a statistically significant difference between the pentoxifylline and sivelestat groups $(p<0.05)$. These data are listed in Table 1.

\section{CD31-antiPECAM Immunostaining Results}

Sivelestat increased CD31-antiPECAM (Platelet endothelial cell adhesion molecule) staining, showing marked angiogenesis and attenuated apoptosis in degloved flaps.

Ischemia-reperfusion injury treated by Sivelestat and Pentoxifylline was followed by an increase in the density of CD31+ capillaries. In Sivelestat treated animal, capillaries increased to almost $150 \%$ of the baseline in Sivelestat treated animals and in Pentoxifylline treated animals, to $100 \%$ of baseline. The rate of angiogenesis (CD31+ cells) was analyzed in a blinded way by counting numbers of cells or profiles in four defined regions of interests per tissue measuring $62.500 \mu \mathrm{m}^{2}$ and the results are shown in Table 2 . These results suggest that Sivelestat could effectively promote vascular endothelial cells leading to angiogenesis by neutrophil-elastase inhibition compared with Pentoxifylline treated groups $(p<0.05)$.

TUNEL Assay Results: Positive TUNEL-stained cells were detected and quantified in the dermis and hypodermis of avulsed flaps during the wound healing in all groups. Nucleus of TUNEL $(+)$ cells were marked by an increase in intensity of nuclear fluorescence by changing their fluorescence from dark blue (normal cells) to a bright blue, white color, indicating chromatin condensation. As shown in Figure $5 \mathrm{a}-\mathrm{c}$, the TUNEL positive cell number was significantly decreased by Sivelestat treatment on day seven, compared to the other two groups $(p<0.05, p<0.01$, respectively). The apoptotic cells were counted in four randomly chosen areas of the dermis and the comparison between the groups are presented in Figure 6.

\section{Discussion}

Treatment of circumferentially avulsed flaps with selective neutrophil-elastase inhibitor, Sivelestat ${ }^{\circledR}$ reduced apoptotic cell death and enhanced endothelial wound healing, as well as angiogenesis, which was shown through TUNEL assay and activity of CD31 anti-PECAM antibodies. To our knowledge, this is the first study to examine the consequences of degloving injury on the basis of an ischemiareperfusion injury, since the circumferentially degloved segment becomes a reversely perfused flap going through the phases of the IRI sequela.

We have previously shown that Sivelestat ameliorates ischemia-reperfusion injury in a muscle flap model when administered at a dosage of $10 \mathrm{mg} / \mathrm{kg} / \mathrm{hour}$. In this study, Sivelestat was utilized on an animal degloving injury model described by Milcheski et al. and the ischemia-reperfusion ameliorating effects of Sivelestat was compared with Pentoxifylline. However, these prementioned studies were designs of experimental degloving injury models. They only compared the flap results concerning planimetry and percentages of necrotic areas, which were determined only macroscopically.

Many factors play a role before a decision is made about

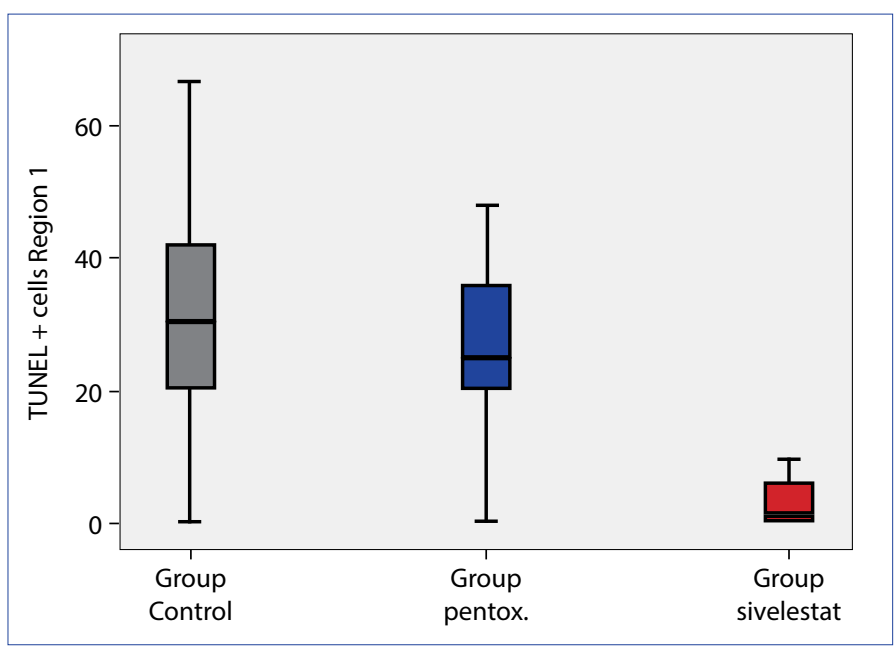

Figure 6. Representation of the statistical analysis between groups with regards to TUNEL (+ cells in region 3 of the avulsed flap. 
the treatment protocol in degloving injuries. The age of the patient, hand dominance, and occupation of the patient are important considerations in choosing the reconstruction method. The principles of management include preserving as much of the structures as possible, providing early primary skin coverage, and allowing the early return of function. Choices of treatment methods are thoroughly discussed throughout the literature. ${ }^{[15]}$ In instances of circumferential single plane degloving of the skin, the degloving is usually between the deep fascia and the subcutaneous fascia and skin. Mac Collum recommended conservative management in 26 "wringer" injuries that caused circumferential single plane degloving. ${ }^{[16]}$ In his treatment algorithm, conservative management composed of removing the subcutaneous hemorrhage and nonviable fat tissue followed by drainage and pressure dressings. The simplest and most frequently used treatment in degloving injuries over the deep fascia is to re-suture the avulsed flap. Many authors recommend wound debridement and coverage of the defect with skin grafts, perhaps harvested from the avulsed flaps. ${ }^{[17]}$ Microsurgical techniques may be used as described by Waikakul, where avulsed flaps are used as perforator-based flaps. ${ }^{[18]}$ The VAC ${ }^{\mathrm{TM}}$ therapy $(\mathrm{KCl}$, Inc., San Antonio, Texas) has been proven to be useful in the management of the degloved foot since it provides a secure contact of the graft with the bed. Dermal substitutes have been tried in degloving injuries with relative success. ${ }^{[19,20]}$ However, the cost-effectivity of the latter two techniques is arguable.

Endothelial dysfunction is one of the characteristics of ischemia-reperfusion injury. De With et al. ${ }^{[21]}$ reported that reperfusion injury impairs ascending vasodilation in the feeding arteries of hamster skeletal muscle. In our study, Sivelestat induced angiogenesis through providing endothelial recovery in the avulsed flap, which have been shown by CD31 immunofluorescence staining and the results are statistically significant compared with the control group and the pentoxifylline group. Upholding endothelial recovery enhanced the surviving length of the degloved segment of the flap.

Degloving injury may exert both early and late complications. Early complications, such as serious infection, distal ischemia, may currently be dealt with the use of neutrophil-elastase inhibitor. Therefore, another important part that needs to be put forward in this study is the dominant anti-inflammatory properties of neutrophil elastase inhibitors. Neutrophil elastase inhibitors reduce the level of inflammatory mediators by inhibiting NF- $\mathrm{k} \beta$. Elastase is stored in cytoplasmic granules, its' primary role being intracellular degradation of foreign proteins during phagocytosis. It is for this reason that Sivelestat has found use in acute systemic respiratory distress syndrome and in the treatment of shock. ${ }^{[22,23]}$ The release of elastase during postischemic reperfusion may be an important mechanism by which neutrophils cause tissue injury. We have shown in this study that Sivelestat treated groups, present with less inflammation. Pentoxifylline, on the other hand, does not present a marked anti-inflammatory effect. The vasodilatory effects of Pentoxifylline and anti-oxidant properties of Allopurinol stand out more significantly in treating degloving injuries. ${ }^{[10]}$

Our study showed that the amount of DNA fragmentation and chromatin condensation is significantly decreased by the administration of Sivelestat, and the results when compared to Pentoxifylline are more effective in the salvage of the degloved segment $(p<0.05)$.

A reversely-perfused flap can survive via the formation of a direct vascular anastomosis between the recipient and donor area, which usually takes place during the first 72 hours. ${ }^{[24]}$ Sivelestat increases angiogenesis. Therefore, the amount of a direct vascular anastomosis significantly increases when Sivelestat is administered at $10 \mathrm{mg} / \mathrm{kg} / \mathrm{hour}$ dosage. ${ }^{[25-27]}$

\section{Conclusion}

In conclusion, we have demonstrated that Sivelestat treatment improves flap survival in degloved segments by simultaneously attenuating apoptosis and enhancing angiogenesis, which is a unique result of this study. It is our belief that the modulation of anti-PECAM antibodies plays an important role in this response. These findings warrant further investigation of intravenous Sivelestat effects in improving the degree of tissue preservation in degloving injuries of the extremities. Increasing the survived length of the avulsed flap raises the possibility of being able to restore a more normal gait than would be possible using a free flap or other techniques. This conservative treatment modality should be kept in mind for the treatment of extremely soft tissue degloving injuries. It is our premise that an improved understanding of degloving injury mechanisms will result in improved clinical approaches to heal these complex injuries.

\section{Disclosures}

Ethics Committee Approval: The study was approved by the Local Ethics Committee.

Peer-review: Externally peer-reviewed.

Conflict of Interest: None declared.

Authorship contributions: Concept - E.Y., K.Z.S.; Design - K.Z.S.; Supervision - S.K.; Materials - F.I., D.D.; Data collection \&/or processing - F.I., D.D.; Analysis and/or interpretation - K.Z.S., M.V.K.; Literature search - E.Y.; Writing - E.Y.; Critical review - S.K. 


\section{References}

1. Edstrom LE. Management of Degloved Hand. In: Weinzweig N, Weinzweig J, editor. Mutilated Hand. Mosby; 2005. p. 307-21.

2. Arnez ZM, Khan U, Tyler MP. Classification of soft-tissue degloving in limb trauma. J Plast Reconstr Aesthet Surg 2010;63:1865-19.

3. Brooks D, Buntic RF, Kind GM, Schott K, Buncke GM, Buncke HJ. Ring avulsion: injury pattern, treatment, and outcome. Clin Plast Surg 2007;34:187-viii. [CrossRef]

4. Hsu WM, Wei FC, Lin CH, Chen HC, Chuang CC, Chen HT. The salvage of a degloved hand skin flap by arteriovenous shunting. Plast Reconstr Surg 1996;98:146-50. [CrossRef]

5. Lin CT, Chen SG, Chen TM, Dai NT, Chang SC. Free fasciocutaneous flaps for reconstruction of complete circumferential degloving injury of digits. Microsurgery 2013;33:191-7. [CrossRef]

6. Bekerecioğlu M, Kutluhan A, Demirtaş I, Karaayvaz M. Prevention of adriamycin-induced skin necrosis with various free radical scavengers. J Surg Res 1998;75:61-5. [CrossRef]

7. Cuong NT, Abe C, Binh NH, Hara A, Morita H, Ogura S. Sivelestat improves outcome of crush injury by inhibiting high-mobility group box 1 in rats. Shock 2013;39:89-95. [CrossRef]

8. Yang T, Zhang J, Sun L, Zhu X, Li J, Wang J, Chen H, Bao R, Deng $X$, Hou J, Liu Y. Combined effects of a neutrophil elastase inhibitor (sivelestat sodium) and a free radical scavenger (edaravone) on lipopolysaccharide-induced acute lung injury in rats. Inflamm Res 2012;61:563-9. [CrossRef]

9. Isken T, Serdaroglu I, Ozgentas E. The effects of the pentoxifylline on survival of the skin flaps in streptozotocin-diabetic rats. Ann Plast Surg 2009;62:446-50. [CrossRef]

10. Milcheski DA, Nakamoto HA, Tuma P Jr, Nóbrega L, Ferreira MC. Experimental model of degloving injury in rats: effect of allopurinol and pentoxifylline in improving viability of avulsed flaps. Ann Plast Surg 2013;70:366-9.

11. Oztuna V, Eskandari MM, Unal S, Colak M, Karabacak T. The effect of pentoxifylline in treatment of skin degloving injuries: an experimental study. Injury 2006;37:638-41. [CrossRef]

12. Iwata K. The propensity score analysis on the efficacy of sivelestat. Pulm Pharmacol Ther 2013;26:395. [CrossRef]

13. Reitmeir R, Kilic E, Kilic U, Bacigaluppi M, ElAli A, Salani G, et al. Post-acute delivery of erythropoietin induces stroke recovery by promoting perilesional tissue remodelling and contralesional py- ramidal tract plasticity. Brain 2011;134:84-99. [CrossRef]

14. von Kobyletzki G, Heine O, Stephan H, Pieck C, Stücker M, Hoffmann $K$, et al. UVA1 irradiation induces deoxyribonuclease dependent apoptosis in cutaneous T-cell lymphoma in vivo. Photodermatol Photoimmunol Photomed 2000;16:271-7. [CrossRef]

15. Krishnamoorthy R, Karthikeyan G. Degloving injuries of the hand. Indian J Plast Surg 2011;44:227-36. [CrossRef]

16. Maccollum DW, Bernhard WF, Banner RL. The treatment of wringer-arm injuries. N Engl J Med 1952;247:750-4. [CrossRef]

17. Lo S, Lin YT, Lin CH, Wei FC. A new classification to aid the selection of revascularization techniques in major degloving injuries of the upper limb. Injury 2013;44:331-5. [CrossRef]

18. Waikakul S. Revascularization of degloving injuries of the limbs. Injury 1997;28:271-4. [CrossRef]

19. Dini M, Quercioli F, Mori A, Romano GF, Lee AQ, Agostini T. Vacuum-assisted closure, dermal regeneration template and degloved cryopreserved skin as useful tools in subtotal degloving of the lower limb. Injury 2012;43:957-9. [CrossRef]

20. Graham GP, Helmer SD, Haan JM, Khandelwal A. The use of Integra ${ }^{\circledR}$ Dermal Regeneration Template in the reconstruction of traumatic degloving injuries. J Burn Care Res 2013;34:261-6.

21. Zhang Q, Chang Q, Cox RA, Gong X, Gould LJ. Hyperbaric oxygen attenuates apoptosis and decreases inflammation in an ischemic wound model. J Invest Dermatol 2008;128:2102-12. [CrossRef]

22. Kay S, Werntz J, Wolff TW. Ring avulsion injuries: classification and prognosis. J Hand Surg Am 1989;14:204-13. [CrossRef]

23. Urbaniak JR, Evans JP, Bright DS. Microvascular management of ring avulsion injuries. J Hand Surg Am 1981;6:25-30. [CrossRef]

24. Musgrave RH, Lehman JA. Composite grafts. In: Georgiade G, Georgiade NG, Riefkohl R, Barwick WJ, editors. Textbook of plastic, maxillofacial and reconstructive surgery. Baltimore: Williams and Wilkins; 1992. p. 47.

25. Fabia R, Travis DL, Levy MF, Husberg BS, Goldstein RM, Klintmalm $\mathrm{GB}$. Effect of pentoxifylline on hepatic ischemia and reperfusion injury. Surgery 1997;121:520-5. [CrossRef]

26. Liu DX, Li XD, Wang H, Qiu KF, Du SX. Reconstruction of total degloving injuries of the foot in children. J Trauma Acute Care Surg 2012;73:209-14. [CrossRef]

27. Wójcicki P, Wojtkiewicz W, Drozdowski P. Severe lower extremities degloving injuries--medical problems and treatment results. Pol Przegl Chir 2011;83:276-82. [CrossRef] 